\title{
Kerangka Kurikulum Pendidikan Agama Kristen Berbasis Karakter di Perguruan Tinggi
}

\section{Character-Based Christian Religious Education Curriculum Framework in Higher Education}

\author{
Binsen Samuel Sidjabat ${ }^{1)^{*}}$ \\ 1) Prodi Teologi Sekolah Tinggi Alkitab Tiranus Bandung \\ *Penulis korespondensi: bssidjabatll@yahoo.com
}

Received: 19 September 2018/Revised: 12 December 2018 /Accepted: 02 February 2019

\begin{abstract}
Abstrak
Artikel ini mengusulkan sebuah kerangka kurikulum Pendidikan Agama Kristen (PAK) berbasis karakter di perguruan tinggi umum. Untuk mewujudkannya maka berturut-turut dijelaskan konsep pendidikan karakter menurut iman Kristen, pendidikan karakter di perguruan tinggi, dan kerangka kurikulum PAK di perguruan tinggi umum. Kemudian, diungkapkan sebuah kerangka kurikulum PAK mengakomodasi pendidikan karakter.

Kata-kata kunci: pendidikan karakter, PAK, perguruan tinggi, kurikulum.

Abstract

This article proposes a curriculum framework of character-based Christian religious education in higher learning institutions. To make it happen, the concept of character education according to the Christian faith is explained, character education in universities is disclosed, and the Christian religious education curriculum framework is described. Then, the author proposes a Christian religious education curriculum framework based on character education.
\end{abstract}

Keywords: character education, Christian religious education, higher education, curriculum

\section{Pendahuluan}

Mata kuliah Pendidikan Agama Kristen (PAK) di perguruan tinggi umum adalah mata kuliah wajib yang diajarkan, sebagaimana ditekankan oleh undang-undang pendidikan nasional dan pendidikan 
tinggi. ${ }^{l}$ Sesuai dengan ketetapan pemerintah ada sembilan materi pokok yang dipelajari mahasiswa dalam mata kuliah Pengembangan Kepribadian melalui PAK, yaitu: Tuhan; manusia; hukum; moral; ilmu pengetahuan, teknologi dan seni (Ipteks); kerukunan antar umat beragama; masyarakat; budaya; dan politik. ${ }^{2}$ Dosen pengampu mata kuliah dapat menggunakan sembilan topik tersebut dalam mempercakapkan iman Kristen bersama mahasiswa tahun pertama di Perguruan Tinggi, supaya kepribadian mereka mencerminkan iman yang dianut.

Dalam rangka membangun manusia Indonesia yang berwatak luhur sebagaimana ditegaskan oleh tujuan pendidikan nasional (UU Sisdiknas No. 20 Tahun 2003, Pasal 3), maka pendidikan karakter wajib pula dikelola oleh sekolah, dan perguruan tinggi. Pendidikan karakter selain perlu diberikan dalam bentuk kegiatan belajar formal, juga dilakukan melalui pembiasaan, dan pembudayaan yang dikembangkan oleh lembaga pendidikan. Peraturan pemerintah menegaskan bahwa pembentukan, dan pengembangan karakter anak bangsa di tanah air bukan hanya tugas sekolah tetapi juga tugas keluarga, dan masyarakat. ${ }^{3}$

Beberapa tahun terakhir ini mengemuka wancana, dan diskusi tentang bagaimana pendidikan karakter disosialisasikan secara efektif melalui pembelajaran di sekolah dasar dan menengah. Para guru, dan dosen memiliki kesempatan untuk merencanakan dan mengelola kegiatan belajar, yang menjadikan aktivitas itu sebagai instrumen pembentukan, dan pengembangan karakter. PAK dalam konteks sekolah juga sudah tidak lagi dipandang sebagai pembelajaran ajaran keyakinan iman gereja (dogma), melainkan sebagai penanaman nilai-nilai Kristen.

${ }^{1}$ Undang-Undang R.I. Nomor 20 Tahun 2003 Tentang Sistem Pendidikan Nasional, Pasal 12. 1) a; dan Undang-Undang R.I. No. 12 Tahun 2012 tentang Pendidikan Tinggi, Pasal 10; 2), dan Pasal 35; 3) yang menekankan bahwa kurikulum Perguruan Tinggi wajib memuat mata kuliah Agama, Pancasila, Kewarganegaraan, dan Bahasa Indonesia.

${ }^{2}$ Keputusan Direktur Jenderal Pendidikan Tinggi Departemen Pendidikan Nasional Republik Indonesia Nomor: 43/Dikti/Kep/2006 tentang Rambu-Rambu Kelompok Mata Kuliah Pengembangan Kepribadian di Perguruan Tinggi. Dalam Pasal 4 dikemukakan sembilan substansi kajian dalam Pendidikan Agama. Bertolak dari ketetapan itu, Tim Pengembang Matakuliah Pengembangan Kepribadian Pendidikan Agama Kristen, Direktorat Jenderal Pendidikan Tinggi Departemen Pendidikan Nasional, kemudian menetapkan sembilan substansi kajian dalam matakuliah PAK di Perguruan Tinggi (Lase, 2007).

${ }^{3}$ Peraturan Pemerintah Republik Indonesia Nomor 17 Tahun 2010 Tentang Pengelolaan dan Penyelenggaraan Pendidikan, Pasal 67, 76-77, 97; dan Peraturan Presiden Republik Indonesia No. 87 Tahun 2017 Tentang Penguatan Pendidikan Karakter; serta Peraturan Menteri Pendidikan dan Kebudayaan Republik Indonesia Nomor 20 Tahun 2018 Tentang Pendidikan Karakter Pada Satuan Pendidikan Formal. 
Saat ini belum tampak buku pedoman PAK berbasis karakter bagi dosen PAK di perguruan tinggi umum. Maka, dapat diduga bahwa kerangka kurikulum yang memuat garis besar atau pokok pemikiran dan substansi kajian dibutuhkan oleh dosen untuk dikembangkan mengelola perkuliahan. Besar kemungkinan tidak sedikit dosen PAK yang belum memahami hakikat, tujuan, dan metode pendidikan karakter dalam perspektif Kristen. Dosen merasa percaya diri untuk mengelola perkuliahan bila telah memiliki pengetahuan, dan spiritualitas iman untuk diajarkan kepada mahasiswa. Oleh karena belum tersedianya kerangka kurikulum itulah diperlukan percakapan tentang bagaimana sembilan topik PAK di perguruan tinggi umum dapat dihubungkan dengan pengembangan nilai hidup dan karakter jujur, cerdas, tangguh dan peduli, yang patut dipahami oleh mahasiswa.

Pendidikan karakter di Indonesia untuk memelihara dan mempertahankan nilai-nilai bersama, maka proses pendidikan digunakan sebagai sarana untuk mempromosikan perilaku, dan sikap yang baik, menghargai perbedaan dan perbedaan, dan kecenderungan untuk menghadapi dunia yang semakin kompetitif. Kurikulum resmi mengharuskan para pendidik untuk mengajarkan nilai-nilai dengan cara yang bertujuan untuk mempersiapkan kaum muda menuju dunia yang kompetitif serta membangkitkan energi kembali identitas nasional mereka. ${ }^{4}$ Dalam hal ini, pendidik dapat membantu peserta didik untuk mengaktualisasikan setiap domain pembelajaran melalui formulasi kompetensi, dan peserta didik secara bersamaan dapat melakukan tindakan moral yang relevan. Mengintegrasikan nilai-nilai karakter bangsa ke dalam kurikulum dapat dilakukan dalam tiga tahap: pengantar, implementasi, dan evaluasi. ${ }^{5}$ Tulisan ini membentuk kerangka kurikulum PAK berbasis karakter di Perguruan Tinggi.

\section{Metode}

Untuk menghasilkan tulisan ini penulis melakukan penelitian kualitatif yaitu library research. Pertama, dilakukan studi Alkitab dan referensi terkait termasuk di dalamnya uku-buku tafsiran untuk menyediakan pemahaman bagi dosen PAK mengenai konsep karakter dan pembentukannya. Kedua, ditinjau pedoman pendidikan karakter dalam konteks sekolah dan perguruan tinggi, khususnya naskah akademik yang ditetapkan oleh pemerintah melalui Kementerian

\footnotetext{
${ }^{4}$ Uswatun Qoyyimah, "Inculcating Character Education through EFL Teaching in Indonesian State Schools," Pedagogies: An International Journal 1l, no. 2 (April 2, 2016): 3.

${ }^{5}$ Anik Ghufron, "Integrasi Nilai-nilai Karakter Bangsa Pada Kegiatan Pembelajaran," Cakrawala pendidikan: Jurnal Ilmu Pendidikan XXIX, no. 3 (2010): 13.
} 
Pendidikan Nasional. Ketiga, ditelaah pedoman PAK di perguruan tinggi yang menjadi buku pegangan dosen dan mahasiswa. Penelitian itu bersifat konstruktif dalam arti mengemukakan suatu usulan tentang garis besar materi kurukulum PAK berbasis karakter di peguruan tinggi umum. Untuk memperlengkapi usulan itu, ditelaah pula tulisan tentang sebuah model pembelajaran karakter dari perspektif Kristen. Hal itu dilakukan mengingat kurikulum sangat erat dengan pembelajaran. Fokus perhatian ditujukan kepada lima jalur yang dikemukakan N. T. Wright, ${ }^{6}$ yang hasilnya berupa paparan ringkas yang berguna bagi dosen dalam mengelola perkuliahan PAK berbasis karakter.

\section{Pembahasan}

Tidak sedikit dosen PAK memahami bahwa tugasnya hanyalah mengajarkan pokok-pokok keyakinan Kristen berdasarkan Alkitab secara sistematis. Sebab, selain memberi kuliah, dosen PAK kerap membina warga jemaat melalui katekisasi supaya memiliksi pengetahuan iman. Karena itu mereka sangat akrab dengan topik Allah Tritunggal, manusia, dosa dan keselamatan, tanggung jawab Kristen, etika, moralitas, Gereja, panggilannya, pengharapan Kristen, dan akhir zaman. Namun, tidak tertutup kemungkinan adanya dosen memiliki pemahaman sangat terbatas tentang karakter, dan pembentukannya ditinjau dari Alkitab. Dalam kaitan itu, sebelum membahas PAK berbasis karakter uraian di bawah ini dipandang perlu disajikan.

\section{Karakter, dan Pembentukannya: Perspektif Alkitab}

Karakter dapat diartikan sebagai sikap, pola pikir, dan kebiasaan berperilaku yang menjadi ciri khas seseorang. Ramah, jujur, disiplin, kerja keras, menghargai, setia, adil, peduli, belas kasih, rendah hati, kooperatif, merupakan contoh-contoh karakter mulia atau lazim dinamakan virtues. Sebaliknya, kasar, dusta, tidak jujur, sombong, pemarah, iri hati, egois, dan sejenisnya, merupakan sifat-sifat dan kebiasaan buruk yang biasa disebut vices. Karakter merupakan perpaduan hasil belajar dan faktor genetik yang dimiliki seseorang, dan sifatnya berurat berakar dalam hidupnya. Karena itu, dilihat orang lain maupun tidak, orang akan tetap bersikap jujur, disiplin, kerja keras, bertanggung jawab, karena hal-hal itu menggambarkan jati dirinya. ${ }^{7}$ 2010 .

${ }^{6}$ N. T. Wright, After You Believe: Why Character Matters. New York: HarperOne,

${ }^{7}$ B. S. Sidjabat, Membesarkan Anak dengan Kreatif. (Yogyakarta: ANDI, 2008). 
Dosen PAK patut memahami bahwa ada sejumlah istilah dalam Perjanjian Lama yang menggambarkan kata karakter, yaitu: emuna ("kebenaran dan kesetiaan" dalam 1 Samuel 26:23), orah ("perbuatan dan kelakuan" dalam Ayub 34:11; Mzmur 119:9), tam ("ketulusan" atau "integritas" dalam Mazmur 26:1), asur ("langkah" atau "tindakan" dalam Mazmur 44:18-19; Amsal 14:15), emet ("dapat dipercaya" dalam Nehemia 7:2), derek ("jalan" dalam Mazmur 50:23; 2 Raja 22:2; Ulangan 5:33), dan sem ("nama" dalam Mazmur 41:6; Amsal 22:1). Sepuluh hukum utama (Kel. 20:1-17) dan hukum-hukum lain yang diperintahkan untuk ditaati oleh umat Israel menggambarkan karakter yang dikehendaki Allah. Sang Pembebas Israel dari tanah perbudakan Mesir, menghendaki kehidupan umat yang memuliakan Dia dan membangun bagi sesamanya. ${ }^{8}$

Kemudian, kisah-kisah hidup beragam tokoh mencatat adanya karakter yang baik dalam arti berkenan kepada Allah dan orang lain. Contohnya ialah Abraham yang taat, Yusuf yang jujur, Musa yang lemah lembut, Kaleb yang setia, Yeremia yang rela menderita, dan Daniel yang berintegritas. Perjanjian Lama pun merekam tokoh-tokoh yang buruk sikap dan perilakunya, merugikan sesamanya dan dibenci Tuhan, seperti Kain yang penuh benci dan iri, raja Saul yang tidak taat dan angkuh, Absalom yang memberontak, serta raja Nebukadnezar yang lalim. Bukan hanya karakter tokoh yang disingkapkan cerita para tokoh tetapi juga termasuk watak komunitas di sekelilingnya. Kitab Hakim-Hakim, misalnya, menjelaskan karakter Gideon, Yefta, dan Simson yang juga secara tidak langsung menggambarkan karakter di komunitas mereka. ${ }^{9}$

Ajaran tentang karakter juga diperlihatkan oleh kitab-kitab hikmat yakni Ayub yang mengajarkan ketabahan dalam penderitaan, Amsal yang mengemukakan sikap dan jalan-jalan yang baik dan yang buruk, serta Pengkotbah yang menekankan kesia-siaan hidup tanpa takut kepada Tuhan dalam waktu yang terbatas. ${ }^{10}$

${ }^{8}$ David W. Gill, Becoming Good: Building Moral Character (Downer Grove: Inter-Varsity Press, 2000).

${ }^{9}$ Karakter tokoh-tokoh Perjanjian Lama secara komprehensif dibahas dengan baik oleh R. Norman Whybray, The Good Life in The Old Testament (London: T\&T Clark, 2002).

${ }^{10}$ D. Michael Cox dan Brad J. Kallenberg, "character" Dictionary of Scripture and Ethics, Editor: Joel B. Green (Grand Rapids, Michigan: Baker Academic, 2011): 127-130. Uraian lebih komprehensif dikemukakan dalam M. Daniel Carroll R. dan Jacqueline E. Lapsley (Editor), Character Ethics and the Old Testament: Moral Dimensions of Scripture. (Louisville: Westminster John Knox Press, 2007). Ajaran karakter dalam kitab-kitab hikmat Israel disingkapkan oleh William P. Brown dalam Character In Crises: A Fresh Approach to the Wisdom Literature of the Old Testament Grand Rapids, Michigan: William B. Eerdmans Publishing Company, 1996; dan Wisdom's Wonder: Character, Creation, and Crisis 
Dalam Perjanjian Baru, istilah yang menggambarkan karakter baik disebut arête. ${ }^{l l}$ Kitab ini juga mengemukakan sejumlah istilah terkait dengan karakter seperti dokime ("ketekunan" dalam Roma 5:4 atau "kesetiaan" dalam Filipi 2:22), ${ }^{12}$ tropos ("jalan atau perilaku hidup" dalam Ibrani 13:5), katastema ("berperilaku hidup sebagai orang-orang beribadah" dalam Titus 2:3), semnos ("yang mulia" atau "yang luhur" dalam Filipi 4:8; "perilaku terhormat" dalam 1 Tim. 3:8, 11 dan Titus 2:2). Contoh-contoh tabiat buruk (vices) yang berlawanan dengan akhlak mulia (virtues) dapat ditemukan dalam 1 Korintus 6:9, 10; Galatia 5:19-21; Efesus 4:25-32; 5:3-5; dan Kolose 3:5-8.13

Konsep karakter juga diperlihatkan oleh ajaran tentang hidup sebagai murid Kristus. Tuhan Yesus menegaskan kepada para pengikutNya agar hidup menjadi serupa dengan Dia (Matius 10:24-25; Lukas 6:40). Ajaran-Nya mengenai "dengan melihat buah mengenali jenis pohon" (Matius 7:16-20; Lukas 6:43-44) tampak mengindikasikan bahwa karakter menggambarkan diri seseorang. ${ }^{14}$ Karena itulah Tuhan memberi

in the Bible's Wisdom Literature (Grand Rapids, Michigan: William B. Eerdmans Publishing Company, 2014).

${ }^{11}$ Perlu dicatat di sini bahwa kata Yunani arête terdapat dua kali dalam 2 Petrus 1:5 dan tiga lainnya dalam 2 Timotius 1:9 dan Titus 3:5. Selain itu, arête disebut dalam 2 Petrus 1:3, Filipi 4:8 dan 1 Petrus 2:9 (perbuatan baik atau terpuji). Istilah arête dipergunakan guna menyatakan keunggulan moral (moral excellence atau virtue). Daftar kata kekuatan moral (virtues) dalam 2 Petrus 1:5-7 diberi bentuk teologis karena diawali oleh iman (pistis), dan diakhiri oleh kasih (agape). Lihat T. L. Donaldson, "virtue," Geoffrey W. Bromiley (Editor), The International Standard Bible Encyclospedia, Volume Q-Z. (Grand Rapids, Michigan: William B. Eermands Publishing Company, 1979), 993-994.

${ }^{12}$ Kata benda Yunani dokime berasal dari kata sifat dokimos yang berarti diakui (approved), teruji (tried and true) serta sejati (genuine). Kata dokime dalam Roma 5:4 itu menunjuk kepada orang yang karakternya dapat dipercaya, diandalkan, atau sudah tahan uji. Lihat G. E. Montgomery, "character," Geoffrey W. Bromiley (Editor), The International Standard Bible Encyclopedia, Volume A-D (Grand Rapids, Michigan: William B. Eermands Publishing Company, 1979), 634.

${ }^{13}$ Kata-kata lain yang menggambarkan virtues dalam Filipi 4:8 itu ialah "yang benar" (alethe), "yang adil" (dikaia), "yang suci" (hagna), "yang manis" (prosphile), "yang sedap didengar" (euphema), "yang disebut kebajikan" (arête), dan "yang patut dipuji" (apainos). Kata-kata itu bahkan yang lebih banyak lagi tampak pula dalam Kolose 3:12 dan 1 Tim. 3:2-4; 8-11; serta dalam Titus 2:2-10). Artinya, surat-surat kiriman rasul Paulus kepada jemaat perdana, memuat banyak kata yang menggambar karakter dan memberi nasihat, dan petunjuk tentang hidup beriman kepada Tuhan Yesus dengan berbudi pekerti luhur.

${ }^{14}$ D. Michael Cox, dan Brad J. Kallenberg, 128-129. Diskusi tentang karakter dalam Perjanjian Baru dikemukakan secara lebih komprehensif oleh karya Robert L. Brawley (Editor), Character Ethics and the New Testament: Moral Dimensions of Scripture (Lousiville: Westminster John Knox Press, 2007). 
pengajaran bagi murid-Nya dalam beragam kesempatan, termasuk yang diringkaskan oleh Matius dalam Kotbah di Bukit khususnya tentang "kebahagiaan" (Mat. 5:3-12), di samping penjelasan mengenai diri-Nya sebagai yang "penuh belas kasih" (esplanchnisthe) (Mat. 9:36), yang "lemah lembut" (praus), dan "rendah hati" (tapeinos) (Mat. 11:28-30). Kehidupan para murid Yesus dan perangai tokoh-tokoh agama Yahudi menghadapi Kristus, sebagaimana dikisahkan oleh kitab-kitab Injil, dapat pula meningkatkan pengertian tentang karakter bagi kita. ${ }^{15}$

Bagian lain dalam Perjanjian Baru yang menyingkapkan karakter ialah 1 Korintus 13:4-7 yang berbicara mengenai kasih (agape) disertai ciri-cirinya. Kitab 1 Korintus 13:13 terkenal dengan penyebutan tiga karakter yang patut dikembangkan warga jemaat yakni: iman (pistis), pengharapan (elpis) dan kasih (agape). ${ }^{16}$ Buah Roh yang disebut dalam Galatia 5:22-23 pun merupakan karakter, yaitu: kasih (agape), sukacita (khara), damai sejahtera (eirene), kesabaran (makrotumia), kemurahan (khrestotes), kebaikan (agathosune), kesetiaan (pistis), kelemahlembutan (prautes), dan pengendalian diri (engkrateian). Dalam kitab 2 Petrus 1:1-517 terdapat nasihat agar membangun iman (pistis) dengan kebajikan (arete), pengetahuan (gnosin), pengendalian diri (enkrateian), ketekunan (hupomonen), kesalehan (eusebeian), kasih persaudaraan (philadelphian) dan

${ }^{15}$ Lihat studi yang sangat komprehensif dalam Steven A. Hunt, Francois Tolmie dan Ruben Zimmermann, Character Studies in the Fourth Gospel: Narrative Approaches to Seventy Figures in John (Grand Rapids, Michigan: William B. Eerdmans Publishing Company, 2013).

${ }^{16}$ Richard N. Longenecker menyebut 1 Korintus 13:4-7 sebagai daftar kekuatan moral Kristen kontras dengan daftar perangai buruk sebelumnya, "buah kedagingan" (5:19-21). Richard N. Longenecker, Word Biblical Commentary: Galatians (Nashville: Thomas Nelson, 1990), 258-267.

${ }^{17}$ Richard J. Bauckham menyebut perikop ini sebagai the catalog of virtues dimana istilah arête (kebajikan) merupakan kekuatan karakter bersifat helenistik (bd. Filipi 4:8). Iman (pistis) bisa berarti kesetiaan dan merupakan daftar etika Kristen (bd. Galatia 5:22; 1 Timotius 4:12; 6:11; 2 Timotius 2:22; Titus 2:2; Whayu 2:19). Pengetahuan (gnosin) dapat berarti pengetahuan tentang Allah atau pengetahuan filosofis (bd. 2 Korintus 6:6; 8:7). Pengendalian diri (enkrateian) mengandung arti menguasai hawa nafsu anggota tubuh dan emosi (bd. Galatia 5:23; Kisah 24:25; 1 Korintus 9:7; 9:25; Titus 1:8). Ketekunan (hupomonen) artinya bertahan dalam penderitaan atau godaan si jahat (bd. Roma 5:3-4; 1 Timotius 6:11; 2 Timotius 3:10; Titus 2:2; Wahyu 2:19). Kesalehan (eusebeian) merupakan kekuatan karakter menjaga kekudusan hidup (bd. 1 Timotius 6:11). Kasih persaudaraan (philadelphian) banyak ditekankan dalam jemaat mula-mula (bd. Roma 12:10; 1 Tesalonika 4:9; Ibrani 13:1; 1 Petrus 1:22). Ka terhadap semua orang (agape) terdapat dalam bagian-bagian kitab lainnya (bd. 2 Korintus 6:6; Galatia 5:22; Efesus 4:2; 1 Timotius 4:12; 6:11; 2 Timotius 2:22; 3:10; Titus 2:2; Wahyu 2:19). Lihat Word Biblical Commentary: Jude, 2 Peter (Nelson Reference \& Electronic, 1983), 174-183. 
kasih kepada semua orang (agape). Semua sifat baik itu bukanlah hasil upaya pribadi melainkan buah kasih karunia Allah akibat beriman kepada Tuhan Yesus Kristus (bd. 2 Petrus 1:3). ${ }^{18}$

\section{Kerangka Pendidikan Karakter di Perguruan Tinggi}

Pendidikan karakter di Indonesia berfungsi memperbaiki karakter warga negara Indonesia yang bersifat negatif, dan memperkuat peran keluarga, satuan pendidikan, masyarakat, dan pemerintah untuk ikut berpartisipasi dan bertanggung jawab dalam pengembangan potensi manusia atau warga negara menuju bangsa yang berkarakter, maju, mandiri, dan sejahtera. ${ }^{19}$ Identitas nasional yang dimiliki Indonesia telah dilestarikan melalui kurikulum pendidikan, sementara pendidikan Amerika, dan literaturnya telah memengaruhi kurikulum pendidikan Indonesia. ${ }^{20}$ Saat ini himbauan Presiden Republik Indonesia tentang penguatan karakter mulai dari level pendidikan terkecil yaitu Anak Usia Dini hingga perguruan Tinggi menekankan pentingnya pendidikan karakter ini dilakukan. Nilai-nilai karakter bangsa tersebut dituangkan menjadi delapan belas karakter bangsa.

Di tingkat pendidikan dasar dan menengah dikenal delapan belas nilai-nilai hidup yang diharapkan menjadi karakter bangsa, yang patut dipahami oleh murid yaitu: religius, jujur, toleransi, disiplin, kerja keras, mandiri, demokratis, rasa ingin tahu, semangat kebangsaan, cinta tanah air, menghargai prestasi, bersahabat/komunikatif, cinta damai, gemar membaca, peduli sosial dan tanggung jawab. Semua itu dikembangkan berdasarkan falsafah bangsa yaitu Pancasila, nilai-nilai kemanusiaan dan ajaran agama. ${ }^{21}$ Dalam lingkup perguruan tinggi terdapat penyempitan, sebab diusulkan hanya empat karakter utama yang patut ditumbuh kembangkan dalam kehidupan mahasiswa, yaitu jujur, cerdas, tangguh,

${ }^{18}$ Lihat W.N. Kerr, "virtue, virtues," Editor: Walter A. Elwell, Evangelical Dictionary of Theology (Grand Rapids, Michigan, 1984), 1146; dan Veryn D. Verbrugge, The NIV Theological Dictionary of New Testament Words. (Paternoster Press, 2000), 170-171.

${ }^{19}$ Rosa Susanti, "Penerapan Pendidikan Karakter Di Kalangan Mahasiswa," AL Ta lim 20, no. 3 (November 21, 2013): 483.

${ }^{20}$ Anita Abbott, "Indonesian Identity and Cultural Values," in Educational Sovereignty and Transnational Exchanges in Post-Secondary Indonesian Education, by Anita Abbott (Cham: Springer International Publishing, 2017), 148, accessed March 3, 2019, http://link.springer.com/10.1007/978-3-319-53985-0_6.

${ }^{21}$ Pengembangan Pendidikan Budaya dan Karakter Bangsa: Bahan Pelatihan, Kementerian Pendidikan Nasional, Badan Penelitian \& Pengembangan, Pusat Kurikulum, 2010:9-10; Kemendiknas. Panduan Pelaksanaan Pendidikan Karakter (Jakarta: Badan Penelitian dan Pengembangan, Pusat Kurikulum dan Perbukuan, 2011). 
dan peduli, yang disingkat dengan judastali. ${ }^{22}$ Bisa diduga alasannya karena empat belas jenis nilai lainnya sudah ditanamkan oleh para guru di sekolah.

Menarik pula mengamati bahwa yang pertama ditekankan ialah kejujuran, mengingat banyak praktik plagiarism, dan ketidakjujuran akademik lainnya di perguruan tinggi dalam bidang studi apapun. Karena nilai ini tidak ditumbuh kembangkan dalam perguruan tinggi, maka dapat diduga banyak penyandang gelar akademik justru korupsi ketika mereka menjadi pejabat negara atau manajer di perusahaan swasta. Kebijakan pendidikan karakter perguruan tinggi untuk membangun kejujuran dibutuhkan kecerdasan dan ketangguhan. Diduga bahwa jika lulusan perguruan tinggi giat belajar dan terampil membangun pengetahuan, maka diharapkan mereka secara kritis dapat membedakan yang baik dengan yang buruk. Mereka mampu bertahan jujur menghadapi godaan penyimpangan. Secara tersirat dipesankan bahwa karakter peduli perlu disosialisasikan oleh perguruan tinggi agar mahasiswa membaktikan dirinya mencari solusi bagi persoalan sosial dan alam.

Keempat karakter itu diusulkan supaya dipelajari mahasiswa melalui empat pendekatan. Pertama, aktivitas olah hati (emotional activities) yang dianggap bermanfaat untuk membangun karakter jujur, beriman, taqwa, amanah, adil, bertanggung jawab, berempati, berani mengambil resiko, pantang menyerah, rela berkorban dan berjiwa patriotik. Kedua, kegiatan olah pikir (intellectual activities) yang dipandang berguna membangun dan membiasakan cara berpikir cerdas, kritis, kreatif, inovatif, ingin tahu, berpikir terbuka, produktif, dan reflektif. Ketiga, kegiatan olah raga (physical and kinesthetic activities) yang dipahami memotivasi pembiasaan hidup tangguh, bersih, sehat, disiplin, sportif, andal, berdaya tahan, bersahabat, kooperatif, determinatif, kompetitif, ceria dan gigih. Keempat, aktivitas olah rasa dan karsa (affective activities) yang diperkirakan dapat memunculkan dan membiasakan karakter peduli, ramah, menghargai, suka menolong, gotong royong, nasionalis, mengutamakan kepentingan umum, bangga menggunakan produk dan bahasa nasional, dinamis, kerja keras dan beretos kerja. Keempat pendekatan itu ditegaskan saling berkaitan dan diusulkan agar bersinergi dalam membentuk perilaku berkarakter.

Keempat pendekatan itu tampaknya selaras dengan iman kristiani mengenai manusia yang memiliki dimensi fisik (raga), psikologis (pikiran, perasaan, dan sikap), serta dimensi roh, hati, dan suara hati

\footnotetext{
${ }^{22}$ Kementerian Pendidikan Nasional, Direktorat Jenderal Pendidikan Tinggi. Naskah Akademik Pendidikan Karakter di Perguruan Tinggi, 2011.
} 
atau syneidesis (bdg. 1 Tesalonika 5:23; Markus 12:29, 30; Ibrani 9:14). Patut dipahami bahwa manusia bukan saja berdimensi individu tetapi juga berdimensi sosial sehingga ia dibutuhkan oleh dan membutuhkan sesamanya (bdg. Kejadian 1:26-27; Amsal 1 27:17), di samping berdimensi kosmologis di mana ia terikat kepada lingkungan alamnya (Kejadian 1:28-29; Roma 8:18-20). Dengan pengertian itu, dosen patut menuntun mahasiswa mengembangkan karakter baik melalui aktivitas olah rasa, olah karsa, olah piker, dan olah raga.

Oleh karena manusia adalah mahluk berdosa maka upaya manusiawi untuk menumbuhkan karakter mulia atau virtue oleh kekuatan dirinya sendiri akan terbatas, bahkan ia menemui kegagalan dan mengalami rasa kecewa. Dalam terang iman Kristen, manusia berkehendak baik namun yang ditemui dalam hati, pikiran dan perilakunya adalah keburukan atau vice (Roma 7:13-25; Galatia 5:22-23). Dalam ajaran Alkitab sebagaimana disinggung di atas, pembentukan virtue merupakan buah pendamaian orang kepada Allah dalam Yesus Kristus, dan oleh transformasi Roh Kudus. Pendidikan dan pembelajaran yang dikelola secara manusiawi agar manusia menjadi serupa dengan gambar Sang Khalik (Roma 8:29; Kolose 3:9,10), jelas membutuhkan pertolongan Tuhan. Di atas landasan inilah pendidikan karakter baik secara tersendiri maupun secara bersama-sama dengan PAK patut dikembangkan, termasuk dalam lingkup perguruan tinggi. Oleh karena itu pula maka gereja dan lembaga gerejawi serta pendidik Kristen, memiliki ruang untuk membantu pewujudan nilai-nilai dan karakter bangsa dalam kehidupan warga jemaat atau anak didik. Terkait dengan tugas itu, maka dosen PAK di perguruan tinggi perlu memikirkan kurikulum yang mengakomodasi pembentukan dan pengembangan karakter.

\section{Kerangka Kurikulum PAK Perguruan Tinggi.}

Supaya PAK di perguruan tinggi dapat mengakomodasi dan memfasilitasi pendidikan karakter mahasiswa, maka kurikulumnya patut dikembangkan terlebih dahulu. Paling sedikit dosen mempunyai sebuah kerangka kurikulum sebagai pedoman mengembangkan desain pembelajaran. Sejauh ini dikenal sembilan substansi kajian yang disarankan pemerintah menjadi pokok bahasan dalam PAK, yaitu: 1) Tuhan Yang Maha Esa dan Ketuhanan; 2) Manusia; 3) Hukum; 4) Moral; 5) IPTEKS; 6) Kerukunan antar umat beragama; 7) Masyarakat; 8) Budaya; 9) Politik. Dalam Materi Ajar Matakuliah Pengembangan Kepribadian: Pendidikan Agama Kristen di Perguruan Tinggi oleh Lase (2007) dan Pendidikan Agama Kristen untuk mahasiswa Universitas Terbuka oleh 
Haba (2008) belum terlihat adanya bahasan mengenai karakter. ${ }^{23}$ Walaupun ada substansi kajian Moral namun bahasan dalam kedua sumber belajar itu tidak mengarah kepada pembentukan nilai dan karakter Kristen. Dapat diduga bahwa kesembilan substansi kajian itu mengemuka sebelum pendidikan karakter digemakan oleh Pendidikan Nasional sejak tahun 2010.

Dalam Buku Ajar Mata Kuliah Wajib Umum Pendidikan Agama Kristen (Kemenristekdikti, 2016), terdapat sembilan substansi kajian perkuliahan PAK. Kesembilan substansi kajian itu mencakup: 1) Agama dan fungsinya dalam kehidupan manusia; 2) Allah dalam Kepercayaan Kristen; 3) Etika dan Pembentukan Karakter Kristiani; 4) Hubungan Iman Kristen dengan Ilmu Pengetahuan, Teknologi dan Seni; 5) Menciptakan Kerukunan Antar Umat Beragama; 6) Penjaga Ciptaan Allah; dan 7) Cara Bergaul yang Baik. Materi PAK ini sudah memuat satu substansi ringkas mengenai pembentukan karakter kristiani.

\section{Kerangka Kurikulum PAK Berbasis Karakter}

Pendidikan karakter yang yang dilaksanakan di sekolah perlu dievaluasi untuk melihat tingkat keberhasilannya, dan bagaimana kurikulum dapat memengaruhi perilaku peserta didiknya. Dari evaluasi tersebut maka pimpinan sekolah dapat membentuk kurikulum yang sesuai kebutuhan peserta didiknya. ${ }^{24}$ Dengan demikian pelaksanan kurikulum berbasis karakter dapat terlaksana dengan baik, dan hasilnya berdampak pada perubahan sikap peserta didik sesuai dengan nilai-nilai karater.

Jika pendidikan karakter diakomodasi oleh perkuliahan PAK, ada dua pertanyaan yang menuntut jawaban: Bagaimana konstruksi desain kurikulum dan pembelajarannya? Bagaimana karakter jujur, cerdas, tangguh dan peduli (judastali) yang ditekankan oleh Naskah Akademik Pendidikan Karakter di Perguruan Tinggi (2011) dapat diintegrasikan dalam pembelajaran sembilan substansi kajian PAK? Untuk menjawab kedua pertanyaan itu, maka setiap substansi kajian patut dihubungkan dengan karakter jujur, cerdas, tangguh dan peduli. Tulisan ini memberi usulan kerangka kurikulum sebagai berikut:

\footnotetext{
${ }^{23}$ Jason Lase (ed.), Materi Ajar Matakuliah Pengembangan Kepribadian: Pendidikan Agama Kristen di Perguruan Tinggi (Bandung: Bina Media Informasi, 2007). Substansi kajian serupa dinyatakan juga dalam Buku Materi Pokok MKDU 4222/3 sks/Modul 1-9, dalam John Haba dkk., Pendidikan Agama Kristen (Jakarta: Penerbit Universitas Terbuka, 2008).

${ }^{24}$ Cletus R. Bulach, "Implementing a Character Education Curriculum and Assessing Its Impact on Student Behavior," The Clearing House: A Journal of Educational Strategies, Issues and Ideas 76, no. 2 (November 2002): 81.
} 


\begin{tabular}{|c|c|c|}
\hline Substansi & Rambu-rambu & Pokok bahasan terkait \\
\hline Kajian & $\begin{array}{l}\text { Pelaksanaan (SK No. } \\
\text { 43/Dikti/Kep/2006) }\end{array}$ & Karakter Kristen \\
\hline $\begin{array}{l}\text { 1. Tuhan Yang Maha } \\
\text { Esa dan ketuhanan }\end{array}$ & $\begin{array}{l}\text { * Keimanan dan } \\
\text { ketakwaan. } \\
\text { * Filsafat Ketuhanan } \\
\text { (teologi) }\end{array}$ & $\begin{array}{l}\text { Tuhan Yang Maha Esa, } \\
\text { Pencipta, Pemelihara, } \\
\text { Pembaru hidup, dan sumber } \\
\text { kejujuran, kecerdasan, } \\
\text { ketangguhan, dan } \\
\text { kepedulian. }\end{array}$ \\
\hline 2. Manusia & $\begin{array}{l}\text { * Hakikat manusia } \\
\text { * Martabat manusia. } \\
\text { * Tanggung jawab } \\
\text { manusia. }\end{array}$ & $\begin{array}{l}\text { * Suara hati dan kejujuran. } \\
\text { * Hikmat, pengetahuan dan } \\
\text { kecerdasan. } \\
\text { *Manusia lemah dan } \\
\text { tangguh. } \\
\text { *Belas kasih dan kepedulian } \\
\text { terhadap sesama. }\end{array}$ \\
\hline 3. Hukum & $\begin{array}{l}\text { * Menumbuhkan } \\
\text { kesadaran untuk taat } \\
\text { hukum Tuhan. } \\
\text { * Fungsi profetik agama } \\
\text { dalam hukum. }\end{array}$ & $\begin{array}{l}\text { *Kejujuran, suara hati dalam } \\
\text { hukum. } \\
\text { * Cerdas, kritis, konstruktif } \\
\text { memahami hukum. } \\
\text { * Tangguh, tidak melanggar } \\
\text { atau memanipulasi hukum. } \\
\text { * Peduli terhadap mereka } \\
\text { yang menjadi korban } \\
\text { ketidakadilan. }\end{array}$ \\
\hline 4. Moral & $\begin{array}{l}\text { * Agama sebagai sumber } \\
\text { moral. } \\
\text { * Akhlak mulia dalam } \\
\text { kehidupan. }\end{array}$ & $\begin{array}{l}\text { Moral berbasis karakter } \\
\text { (virtues); moralitas kejujuran; } \\
\text { Sipa dan perilaku moral } \\
\text { cerdas, kritis, positif, } \\
\text { konstruktif; Moral tangguh, } \\
\text { mandiri, kreatif; dan peduli. }\end{array}$ \\
\hline 5. Ipteks & $\begin{array}{l}\text { * Iman, Ipteks, dan amal } \\
\text { sebagai kesatuan. } \\
\text { * Kewajiban menuntut } \\
\text { dan mengamalkan ilmu. }\end{array}$ & $\begin{array}{l}\text { Kejujuran akademik; cerdas } \\
\text { dan berpikir kritis; } \\
\text { ketangguhan dalam studi } \\
\text { dan penelitian serta } \\
\text { pengembangan seni; dan } \\
\text { kepedulian kepada seni, } \\
\text { tradisi dan kebijakan lokal. }\end{array}$ \\
\hline $\begin{array}{l}\text { 6. Kerukunan antar } \\
\text { umat beragama. }\end{array}$ & $\begin{array}{l}\text { * Agama merupakan } \\
\text { rahmat Tuhan bagi } \\
\text { sesama. } \\
\text { * Kebersamaan dalam } \\
\text { pluralitas agama. }\end{array}$ & $\begin{array}{l}\text { Kejujuran dan integritas di } \\
\text { tengah kemajemukan, } \\
\text { berpikir positif dan kritis, } \\
\text { tangguh menghadapi } \\
\text { tekanan, dan peduli terhadap } \\
\text { penderitaan orang yang } \\
\text { berbeda budaya dan } \\
\text { keyakinan. }\end{array}$ \\
\hline
\end{tabular}




\begin{tabular}{|c|c|c|}
\hline 7. Masyarakat & $\begin{array}{l}\text { * Masyarakat beradab } \\
\text { dan sejahtera. } \\
\text { * Peran umat beragama } \\
\text { dalam mewujudkan } \\
\text { masyarakat beradab dan } \\
\text { sejahtera. } \\
\text { * Hak Azasi manusia } \\
\text { (HAM) dan demokrasi. }\end{array}$ & $\begin{array}{l}\text { Ciri masyarakat beradab dan } \\
\text { sejahtera: menjunjung } \\
\text { kejujuran; menghargai } \\
\text { kecerdasan majemuk, } \\
\text { tangguh, ulet, taat; dan } \\
\text { menghargai perbedaan dan } \\
\text { pedulian sosial. }\end{array}$ \\
\hline 8. Budaya & $\begin{array}{l}\text { * Budaya akademis. } \\
\text { * Etos kerja, sikap } \\
\text { terbuka, dan adil. }\end{array}$ & $\begin{array}{l}\text { * Kejujuran akademis dan } \\
\text { suara hati. } \\
\text { * Cerdas, cendikia. } \\
\text { * Tangguh, ulet, kerja keras, } \\
\text { mandiri. } \\
\text { * Peduli terhadap warisan } \\
\text { budaya dan tradisi luhur. }\end{array}$ \\
\hline 9. Politik & $\begin{array}{l}\text { * Kontribusi agama } \\
\text { dalam kehidupan } \\
\text { politik. } \\
\text { * Peranan agama dalam } \\
\text { mewujudkan persatuan } \\
\text { dan kesatuan bangsa. }\end{array}$ & $\begin{array}{l}\text { * Kejujuran dan hati nurani } \\
\text { dalam menyikapi kekuasaan. } \\
\text { * Cerdas, kritis, kreatif } \\
\text { dalam berpolitik. } \\
\text { * Tangguh, mandiri, kerja } \\
\text { keras, bertanggung jawab. } \\
\text { * Peduli terhadap krisis } \\
\text { politik dan kekuasaan. }\end{array}$ \\
\hline
\end{tabular}

Jika garis besar materi PAK dengan karakter telah diintegrasikan maka proses pembelajarannya juga perlu direncanakan agar dapat berlangsung kreatif bahkan transformatif. Di atas telah dikemukakan bahwa pendidikan karakter di perguruan tinggi dapat dikelola dosen dengan pendekatan olah pikir (kognitif), olah raga (kinestesik), olah rasa (emosi), olah hati (spiritual). Jelas tidak mudah bagi dosen untuk merencanakan dan mengelola kegiatan seimbang, supaya tidak memberi tekanan kepada salah satu pendekatan, misalnya pendekatan kognitif dan spiritual. Tidak sedikit dosen mengajak mahasiswa memiliki pengetahuan tentang karakter dari Alkitab. Diduga bahwa pengetahuan yang benar membuahkan sikap dan perilaku yang baik. Dosen yang cenderung mengajar secara kognitif akan menekankan strategi pembelajaran demikian dengan metode kuliah, tanya jawab, diskusi, seminar, bahkan debat. Agar pemahaman dosen lebih komprehensif, tulisan memandang perlu membicarakan model-model pendekatan pendidikan karakter.

\section{Pembelajaran PAK Berbasis Karakter}

Kurikulum tidak terpisahkan dari pembelajaran. Paling sedikit kurikulum memuat komponen tujuan, bahan, metode, dan penilaian. Jika di atas telah disajikan kerangka kurikulum yang berguna membekali dosen, maka paparan ini menyediakan sumber pemikiran bagaimana 
perkuliahan PAK berbasis karakter dapat berlangsung kreatif dan transformatoris. Dosen tidak akan terjebak menuntun mahasiswa belajar PAK dan karakter hanya dari studi Alkitab dan teologi, tetapi juga dari studi bidang kajian atau komponen lainnya. Penulis memandang konsep Wright dapat berguna dalam perkuliahan PAK dan pendidikan karakter. Walaupun karya yang mengintegrasikan studi Alkitab, teologi dan filsafat tentang karakter ini dinilai oleh Kallenberg ${ }^{25}$ lebih bernuansa Barat, namun ditegaskan bahwa pemikiran Wright bukan hanya mampu mengajak pembina warga gereja memahami karakter tetapi juga termotivasi mengembangkan karakter mereka.

Pakar Perjanjian Baru dan praktisi pendidikan warga jemaat, N. T. Wright, ${ }^{26}$ menjelaskan bahwa jika orang ingin mengalamai perubahan watak maka mereka patut membuka hati dan menyambut kasih karunia Allah, pengampunan dosa, yang dikerjakan oleh Yesus Kristus. ${ }^{27}$ Jika orang sudah mengaku percaya maka selanjutnya ia patut memasuki aktivitas pembentukan dan pengembangan karakter dalam supaya sifatsifat baik (virtues) bertumbuh dalam dirinya. ${ }^{28}$ Perubahan sikap dan perilaku terjadi karena berlangsungnya pembaruan akal budi, sebagaimana dinasihatkan oleh Rasul Paulus dalam Roma 12:2. ${ }^{29}$ Sifat atau perangai luhur yang sepatutnya menguasai pikiran, perasaan, sikap dan praktik hidup orang Kristen ialah iman, kasih, pengharapan (1 Korintus 13:13) dan sembilan dimensi buah Roh (Galatia 5:22-23).30

Selanjutnya, Wright mengusulkan model lingkaran terbuka dimana kelima elemen itu merupakan jendela yang dapat berdiri sendiri sebagai jalan masuk atau bisa juga berututan kepada yang lain. ${ }^{31}$ Pertama, pendidikan karakter kristiani dapat dilakukan melalui jalur Alkitab (Scripture) dimana penelaahannya dikembangkan dengan beragam cara kreatif, termasuk pendekatan tematis, studi biografis dan analisis teks (nats) atau eksposisi. Diakui bahwa Alkitab memiliki kuasa untuk melahirkan perubahan karakter (2 Tim. 3:16-17).

Kedua, jalur kisah kehidupan (Story) orang-orang yang bergumul mewujudkan perlilaku berkarakter. Alkitab menuliskan banyak kisah kehidupan termasuk Abraham, Yakub, Yusuf, Daud, Elia, Elisa, Yesus

${ }^{25}$ Michael J. Kallenberg, "After You Believe: Why Christian Character Matters," Christian Scholar's Review. 40.2 (2011): 231-234. 2012).

${ }^{26}$ N. T. Wright, After You Believe: Why Character Matters (New York: HarperOne,

${ }^{27}$ Wright, 1-26.

${ }^{28}$ Wright, 27-72.

${ }^{29}$ Wright, 135-180.

${ }^{30}$ Wright, 219-256.

${ }^{31}$ Wright, 257-284. 
dan para rasul serta komunitas murid-murid Tuhan di masa lalu. Studi kisah hidup juga dapat dilakukan dengan mempelajarai riwayat orangorang ternama karakternya. Kisah-kisah dari budaya juga dapat dipergunakan untuk mewujudkan pendekatan ini. Singkatnya, berbagi cerita merupakan pendekatan yang baik dalam pendidikan karakter.

Ketiga, jalur teladan (Example) dimana orang belajar dari contoh hidup orang-orang yang berhasil maupun gagal. Rasul Paulus mendesak Titus supaya mendidik orang-orang muda warga jemaat di pulau Kreta di masa lalu dengan menjadikan dirinya teladan perubahan (Titus 2:6,7). Pesan serupa disampaikan oleh Paulus kepada Timotius yang menunaikan tugas pembinaan warga jemaat di kota Efesus (1 Timotius 4:12). Jadi, dosen PAK sendiri patut menjadikan dirinya teladan moral diantara peserta didiknya. Seterusnya peserta didik dapat menjadi teladan bagi sesamanya.

Keempat, jalur komunitas (Community). Pendidik dan peserta didik membangun persekutuan dimana mereka dapat berbagi pengalaman, berdoa, beribadah, saling menasehati, membangun, menegur. Karena itulah mengapa misalnya warga jemaat di kota Kolose dahulu dinasehatkan Paulus untuk membangun komunitas yang saling membantu (Kolose 3:15-17). Pesan serupa ditegaskan oleh beberapa teks Alkitab lainnya (bd. Galatia 6:1-2; Ibranil0:24, 25).

Kelima, jalur praktik (Practices). Bertumbuhnya nilai hidup baru dan pembangunan perilaku berkarakter dapat terjadi melalui keterlibatan dalam sebuah atau beberapa praktik kehidupan seperti membantu korban gempa bumi, menolong orang sakit. Lewat praktik itu rasa belas kasihan, kepedulian, kemurahan, pengorbanan, tanggung jawab, kerjasama, terbangun dan bahkan berkembang. Praktik hidup yang benar menjadi arena latihan yang di dalamnya karya Allah mentransfromasi karakter berlangsung.

Berdasarkan model Wright itu, dosen boleh saja memulai dari jalur yang lebih tepat baginya. Misalnya, dosen membimbing mahasiswa belajar karakter jujur dan tangguh dari tokoh Alkitab seperti Yusuf dan Daniel. Kemudian, kisah hidup tokoh kontemporer yang jujur dan tangguh seperti Yusuf dan Daniel dapat dibahas bersama mahasiswa. Contohnya mereka itu ialah Nelson Mandela, Basuki Tjahaya Purnama dan Jokowi. Banyak sumber belajar yang dapat ditelaah mahasiswa untuk mempercakapkan keteladanan mereka.

Selanjutnya, dosen dan mahasiswa memasuki jalur Alkitab. Maka, ajaran Alkitab khususnya teladan Yesus Kristus mengenai kejujuran dan ketangguhan dibicarakan secara mendalam supaya membangkitkan kebanggan kepada Tuhan. Misalnya, kejujuran Yesus yang dipuji oleh pemimpin agama dan politik dalam Markus 12:13-17. Ketangguhan-Nya 
menghadapi pencobaan (Mat. 4:1-11), penolakan (Mrk. 6:1-6), juga penderitaan dan penyaliban (Yoh. 18-19), dapat dijadikan sumber penelaahan kitab-kitab Injil.

Jalur berikutnya adalah praktik. Dalam kegiatan ini dosen dan mahasiswa mempercakapkan apa saja praktik hidup sehari-hari dalam kejujuran dan ketangguhan. Misalnya, dosen dan mahasiswa dapat membahas praktik membangun kejujuran dalam studi agar tidak tergoda melakukan plagiarism. Dosen dan mahasiswa juga dapat mempercakapkan tindakan konkrit untuk menolak tawaran-tawaran merugikan dalam keuangan, komunikasi, relasi dan pergaulan sehari-hari.

Akhirnya, jalur dukungan. Dosen dan mahasiswa membahas apa yang dapat dan patut dilakukan untuk menguatkan mereka mempraktikkan kejujuran dan ketangguhan selama waktu tertentu, misalnya satu bulan, dapat menjadi doa dan komitmen bersama. Dosen dapat memotivasi mahasiswa membentuk kelompok kecil sebagai sarana mereka saling mengenal lalu berbagi pendapat dan pengalaman, dan saling mendoakan. Hal ini sesuai pula dengan ajaran Perjanjian Baru (Kolose 3:15-16). Kegiatan pertemuan ditetapkan oleh kelompok itu sendiri. Dalam hal demikian dosen PAK berbasis karakter bertindak sebagai komunikator dan gembala. Nuhamara berpendapat pembangunan karakter (Kristiani) melalui PAK sangat perlu khususnya dalam merancang dan mengembangkan kurikulum PAK baik konteks sekolah, komunitas iman Kristen maupun keluarga Kristen. ${ }^{32}$

\section{Kesimpulan}

Pendidikan karakter dan pendidikan agama Kristen (PAK) memiliki peran penting bagi mahasiswa di perguruan tinggi umum di tanah air. Tugas itu memiliki dasar hukum, kebijakan kurikuler, pedagogik, dan landasan Alkitab atau iman Kristen. Panggilan dosen PAK dengan begitu bukan hanya mengelola perkuliahan PAK untuk mengajarkan iman Kristen berdasarkan pokok bahasan Tuhan Yang Maha Esa; Manusia; Hukum; Moral; Ilmu pengetahuan, Teknologi dan Seni (IPTEKS); Kerukunan antar umat beragama; Masyarakat; Budaya; dan Politik, tetapi juga mengembangkan kepribadian dengan memfasilitasi terjadinya transformasi karakter mahasiswa supaya mereka menjadi lulusan yang jujur, cerdas, tangguh dan peduli. Selain perlu memahami karakter dan pembentukannya menurut Alkitab dan tradisi Kristen, dosen PAK patut mempelajari konsep dan pelaksanaan

32 Daniel Nuhamara, "Pengutamaan Dimensi Karakter Dalam Pendidikan Agama Kristen," Jurnal Jaffray 16, no. 1 (2018): 113. 
pendidikan nilai dan karakter bangsa sebagaimana dikemukakan oleh peraturan, kebijakan dan pedoman-pedoman yang dikemukakan pemerintah, selanjutnya diperkaya oleh pendekatan kreatif yang usulan oleh pendidik Kristen.

\section{Kepustakaan}

Abbott, Anita. "Indonesian Identity and Cultural Values." In Educational Sovereignty and Transnational Exchanges in Post-Secondary Indonesian Education, by Anita Abbott, 135-161. Cham: Springer International Publishing, 2017. Accessed March 2, 2019. http://link.springer.com/10.1007/978-3-319-53985-0_6.

Brawley, Robert L. (ed.), Character Ethics and the New Testament: Moral Dimensions of Scripture Lousiville: Westminster John Knox Press, 2007.

Bromiley, Geoffrey W. (ed.), The International Standard Bible Encyclopedia, Volume 2-Z. Grand Rapids, Michigan: William B. Eermands Publishing Company, 1979.

Bulach, Cletus R. "Implementing a Character Education Curriculum and Assessing Its Impact on Student Behavior." The Clearing House: A Journal of Educational Strategies, Issues and Ideas 76, no. 2 (November 2002): 79-83.

Gill, David W. Becoming Good: Building Moral Character. Downer Grove: Inter-Varsity Press, 2000.

Green, Joel B. (ed.) Dictionary of Scripture and Ethics. Grand Rapids, Michigan: Baker Academic, 2011.

Ghufron, Anik. "Integrasi Nilai-nilai Karakter Bangsa Pada Kegiatan Pembelajaran." Cakrawala pendidikan: Jurnal Ilmu Pendidikan XXIX, no. 3 (2010): 13-24.

Haba, John dkk. Pendidikan Agama Kristen. Jakarta: Penerbit Universitas Terbuka, 2008.

Hunt, Steven A., Francois Tolmie dan Ruben Zimmermann. Character Studies in the Fourth Gospel: Narrative Approaches to Seventy Figures in John. Grand Rapids, Michigan: William B. Eerdmans Publishing Company, 2013.

Kallenberg, Michael J. "After You Believe: Why Christian Character Matters.” Christian Scholar's Review 40, no. 2 (2011): 231-234.

Kemendiknas. Panduan Pelaksanaan Pendidikan Karakter. Jakarta: Badan Penelitian dan Pengembangan, Pusat Kurikulum dan Perbukuan, 2011. 
Kementerian Pendidikan Nasional, Direktorat Jenderal Pendidikan

Tinggi. Naskah Akademik Pendidikan Karakter di Perguruan Tinggi, 2011.

Keputusan Direktur Jenderal Pendidikan Tinggi Departemen Pendidikan

Nasional Republik Indonesia Nomor: 43/Dikti/Kep/2006 tentang

Rambu-Rambu Kelompok Mata Kuliah Pengembangan

Kepribadian di Perguruan Tinggi

Lase, Jason (ed.), Materi Ajar Matakuliah Pengembangan Kepribadian:

Pendidikan Agama Kristen di Perguruan Tinggi. Bandung: Bina Media

Informasi, 2007.

Longenecker, Richard N. Word Biblical Commentary: Galatians. Nashville:

Thomas Nelson, 1990.

Nuhamara, Daniel. "Pengutamaan Dimensi Karakter Dalam Pendidikan

Agama Kristen." Jurnal Jaffray 16, no. 1 (2018): 93-114.

Pengembangan Pendidikan Budaya dan Karakter Bangsa: Bahan

Pelatihan, Kementerian Pendidikan Nasional, Badan Penelitian \&

Pengembangan, Pusat Kurikulum, 2010.

Peraturan Menteri Pendidikan dan Kebudayaan Republik Indonesia

Nomor 20 Tahun 2018 Tentang Pendidikan Karakter Pada Satuan

Pendidikan Formal.

Peraturan Pemerintah Republik Indonesia Nomor 17 Tahun 2010

Tentang Pengelolaan dan Penyelenggaraan Pendidikan.

Peraturan Presiden Republik Indonesia No. 87 Tahun 2017 Tentang

Penguatan Pendidikan Karakter

Qoyyimah, Uswatun. "Inculcating Character Education through EFL

Teaching in Indonesian State Schools." Pedagogies: An International Journal 11, no. 2 (April 2, 2016): 1-18.

R., M. Daniel Carroll dan Jacqueline E. Lapsley (ed.). Character Ethics and the Old Testament: Moral Dimensions of Scripture. Louisville:

Westminster John Knox Press, 2007.

Sidjabat, B. S. Membesarkan Anak dengan Kreatif. Yogyakarta: ANDI, 2008.

Susanti, Rosa. "Penerapan Pendidikan Karakter Di Kalangan

Mahasiswa." AL-Ta lim 20, no. 3 (November 21, 2013): 480-487.

Undang-Undang R. I. Nomor 20 Tahun 2003 Tentang Sistem Pendidikan Nasional.

Undang-Undang R.I. No. 12 Tahun 2012 tentang Pendidikan Tinggi.

Verbrugge, Veryn D. The NIV Theological Dictionary of New Testament Words.

Paternoster Press, 2000.

Whybray, R. Norman. The Good Life in The Old Testament. London: T\&T

Clark, 2002.

Wright, N. T. After You Believe: Why Character Matters. New York:

HarperOne, 2010. 